Authors have nothing to disclose with regard to commercial support.

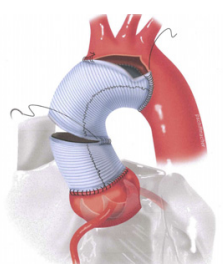

\section{RESECTION OF NONCORONARY SINUS SEGMENT IN A NONANEURYSMAL ROOT: TO DO OR NOT TO DO}

\section{To the Editor:}

We read with keen interest the report by Hui and colleagues ${ }^{1}$ on the stability of nonaneurysmal sinus of Valsalva after aortic valve and ascending aorta replacement in patients with bicuspid aortic valve (BAV) and tricuspid aortic valve (TAV). Of 406 patients followed up, only 1 required reoperation for root dilatation at 22 postoperative years. We congratulate Hui and colleagues ${ }^{1}$ on their excellent outcomes and for adding to the increasing literature supporting sinus of Valsalva preservation in the context of aortic valvulopathy with isolated ascending aorta or arch aneurysm. ${ }^{2-4}$

It is notable that in this study, $36.1 \%$ of patients with BAV (97 of 269) and 19.7\% (27 of 137) of patients with TAV underwent resection and reconstruction of the noncoronary sinus of Valsalva. The mean preoperative sinus segment dimensions were $33 \pm 5 \mathrm{~mm}$ for patients with BAV and $32 \pm 6 \mathrm{~mm}$ for patients with TAV. Indications for noncoronary sinus resection included asymmetric dilatation, advanced age, and BAV morphology with cephalad coronary displacement. Excellent postoperative outcomes are reported, with reoperation for bleeding rates of $10.8 \%$ (BAV) and $13.9 \%$ (TAV). During long-term follow-up, there was no significant sinus segment dilatation, although 124 of the 406 patients who had noncoronary sinus resection were included in this analysis $(30.5 \%$ of the entire study cohort). We express some concern about the inclusion of these 124 patients in the study design and analysis, when the primary question posed is whether the root remains stable or dilates after aortic valve and ascending aorta replacement. A subgroup analysis of the remaining 282 patients with intact sinus of Valsalva may reflect more precisely the question posed in this study.

The results reported by Hui and colleagues ${ }^{1}$ are in concordance with our own experience with the Wheat procedure. ${ }^{4}$ In our investigation of 428 patients, a group that included only patients with complete preservation of sinus of Valsalva,

The Editor welcomes submissions for possible publication in the Letters to the Editor section that consist of commentary on an article published in the Journal or other relevant issues. Authors should: $\bullet$ Include no more than 500 words of text, three authors, and five references. • Type with double-spacing. • See http://jtcs.ctsnetjournals.org/misc/ifora. shtml for detailed submission instructions. • Submit the letter electronically via jtcvs.editorialmanager.com. Letters commenting on an article published in the JTCVS will be considered if they are received within 6 weeks of the time the article was published. Authors of the article being commented on will be given an opportunity of offer a timely response ( 2 weeks) to the letter. Authors of letters will be notified that the letter has been received. Unpublished letters cannot be returned. root stabilization with aortic valve and ascending aorta replacement led to decrease in postoperative sinus dimension, which persisted over long-term follow-up. Mean preoperative sinus dimensions were in fact higher in this study, at $37.4 \pm 4.6 \mathrm{~mm}$ for patients with $\mathrm{BAV}$ and $37.8 \pm 5.9 \mathrm{~mm}$ for patients with TAV. Rates of reoperation for bleeding in subjects with BAV and TAV were $1.97 \%$ and $5.75 \%$, respectively. According to mixed-effects regression analysis, the preserved sinus did not dilate during follow-up when assessed either by valve pathology and morphology or by sinus segment dimension at presentation. Collectively, these data suggest that the sinus segment smaller than $45 \mathrm{~mm}$ can be safely preserved, irrespective of patient age, asymmetric dilatation, or valve morphology. To some extent, this study challenges whether noncoronary segment resection is required on the basis of patient age or morphologic criteria for patients with a sinus segment smaller than $45 \mathrm{~mm}$. Possibly, the higher reoperation for bleeding rates seen in the study of Hui and colleagues ${ }^{1}$ are related to resection and reconstruction of the noncoronary sinus in $30.5 \%$ of their patients.

When it comes to noncoronary sinus reconstruction for a sinus of Valsalva smaller than $45 \mathrm{~mm}$, maybe less is more.

Roland Assi, MD, MMS

Rita Karianna Milewski, $M D, P h D$ Joseph E. Bavaria, MD

Prashanth Vallabhajosyula, $M D, M S$ Division of Cardiovascular Surgery Department of Surgery Hospital of the University of Pennsylvania Philadelphia, $\mathrm{Pa}$

\section{References}

1. Hui SK, Fan CS, Christie S, Feindel CM, David TE, Ouzounian M. The aortic roo does not dilate over time after replacement of the aortic valve and ascending aorta in patients with bicuspid or tricuspid aortic valves. J Thorac Cardiovasc Surg. 2018;156:5-13.e11.

2. Park CB, Greason KL, Suri RM, Michelena HI, Schaff HV, Sundt TM III. Fate of nonreplaced sinuses of Valsalva in bicuspid aortic valve disease. J Thorac Cardiovasc Surg. 2011;142:278-84.

3. Vendramin I, Meneguzzi M, Sponga S, Deroma L, Cimarosti R, Lutman C, et al. Bicuspid aortic valve disease and ascending aortic aneurysm: should an aortic root replacement be mandatory? Eur J Cardiothorac Surg. 2016;49:103-9.

4. Milewski RK, Habertheuer A, Bavaria JE, Siki M, Szeto WY, Krause E, et al. Fate of remnant sinuses of Valsalva in patients with bicuspid and trileaflet valves undergoing aortic valve, ascending aorta, and aortic arch replacement. J Thorac Cardiovasc Surg. 2017;154:421-32.

https://doi.org/10.1016/j.jtcvs.2019.01.036

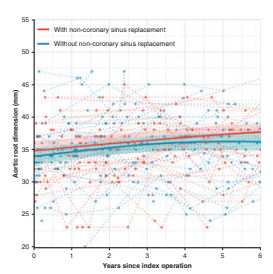

NONCORONARY SINUS SEGMENT: NUANCES OF A DECISION TO RESECT

Reply to the Editor:

We thank Assi and colleagues from the University of Pennsylvania group for their letter regarding our recently-published study on the natural history of the aortic root after replacement of 
Authors have nothing to disclose with regard to commercial support.

the aortic valve and ascending aorta in patients with bicuspid and tricuspid aortic valves. ${ }^{1}$ Their questions regarding the inclusion of patients who underwent replacement of the noncoronary sinus (NCS) in our study are valid and have prompted us to do a subgroup analysis of this subpopulation.

Our results show that patients who underwent replacement of the NCS had larger aortic diameters at baseline than did patients who did not undergo NCS replacement $(P=.042)$. The rate of aortic root diameter increase with time was low in both groups, however, and did not significantly differ between patients who underwent replacement of NCS $(\mathrm{N}=124 ; 0.555 \mathrm{~mm} / \mathrm{year})$ and those who did not ( $\mathrm{N}=282 ; 0.695 \mathrm{~mm} /$ year; $P=.06$; Figure 1$)$. There were also no differences in long-term mortality $(P=.10)$ or aortic reoperation $(P=.97)$ between patients with NCS replacement and those without. In summary, even after excluding patients with NCS replacement from our study, the aortic root diameter still could be seen to increase at a low and clinically negligible rate of $0.695 \mathrm{~mm} /$ year, consistent with our reported results and those published by Milewski and colleagues. ${ }^{2}$

With regard to the question of whether NCS replacement is required in any patient with an aortic root diameter smaller than $45 \mathrm{~mm}$, we maintain that the decision is nuanced and should consider factors beyond the size of the aortic root, age of the patient, and morphology of the aortic valve. A common indication at our institution for NCS replacement is qualitative assessment of the aortic wall tissue. In patients with a very thin aortic wall, replacement of the noncoronary sinus with bovine pericardium is more robust than the native tissue and also allows the placement of a larger prosthetic valve in patients at risk for patient-prosthesis mismatch by seating the sewing ring above the annulus in the pericardial patch. Further studies on the biomechanical properties of the aortic tissue from this group are pending and will help to quantify this assessment. In addition, the suggestion

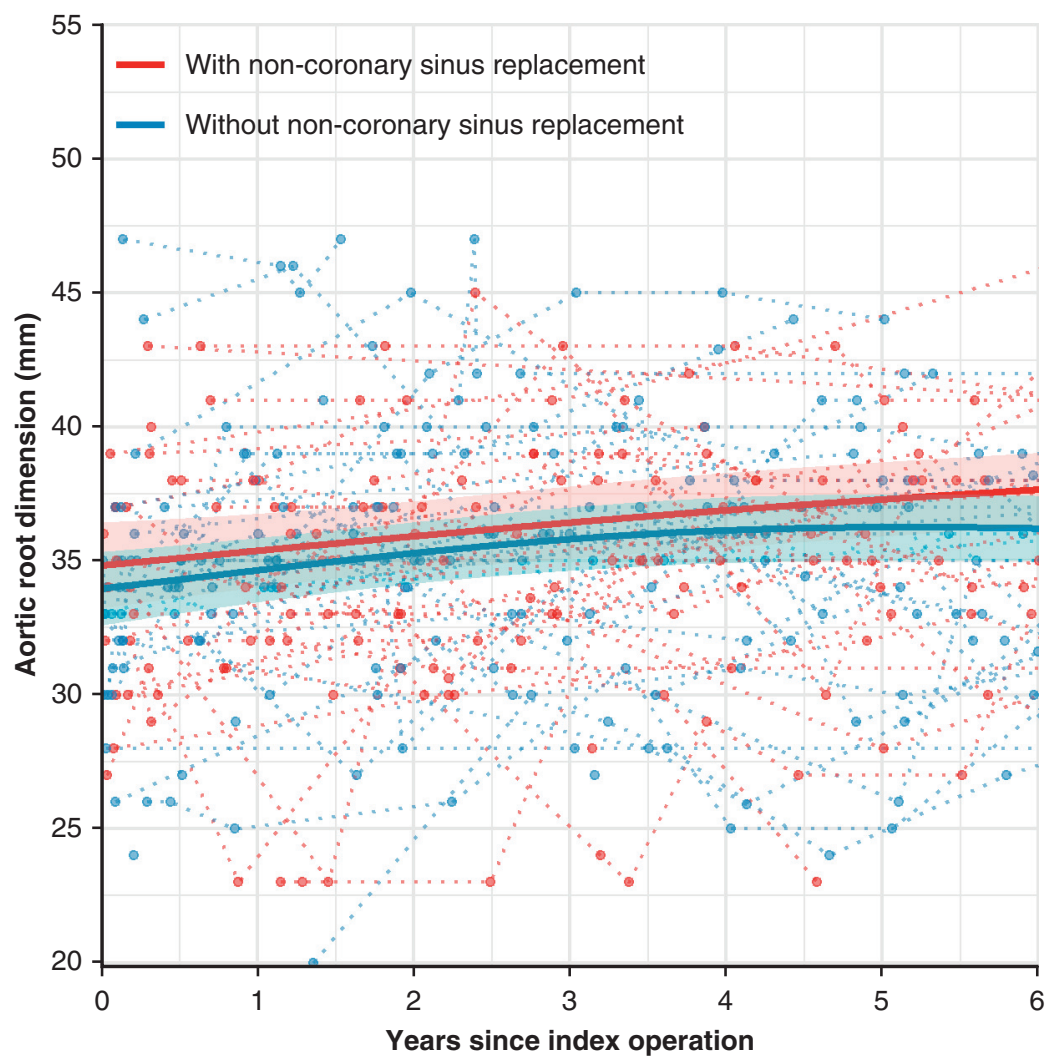

FIGURE 1. Aortic root diameter with time in patients with and without noncoronary sinus replacement. According to the generalized least squares method, after surgical replacement of the aortic valve and ascending aorta, the aortic root increased by $0.555 \mathrm{~mm} / \mathrm{year}$ (95\% confidence interval, $0.048-1.062$; $P=.032)$ in patients with noncoronary sinus replacement and by $0.695 \mathrm{~mm} / \mathrm{year}(95 \%$ confidence interval, $0.291-1.100 ; P<.001)$ in patients without noncoronary sinus replacement. The differential progression rate between patients with and without noncoronary sinus replacement (the difference in the slopes) was not statistically significant $(P=.06)$. 
that increased bleeding rates may be a consequence of NCS replacement is interesting, but it is not supported by our subgroup analysis. Within 30 days after the index operation, $10 \%$ of patients with NCS replacement $(\mathrm{N}=12)$ had a reoperation for bleeding, compared with $13 \%$ of patients without NCS replacement $(\mathrm{N}=36$; $P=.41)$. In summary, on the basis of our clinical experience and new subgroup analysis, we continue to support NCS replacement in selected patients with a baseline aortic root diameter smaller than $45 \mathrm{~mm}$.

Sonya K. Hui, MD, PhD ${ }^{a}$ Christopher M. Feindel, MD, $M S c^{b}$ Maral Ouzounian, $M D, P h D^{b}$

${ }^{a}$ Department of Medicine Faculty of Medicine McGill University Montréal, Québec, Canada ${ }^{b}$ Division of Cardiovascular Surgery Peter Munk Cardiac Centre University Health Network Department of Surgery University of Toronto Toronto, Ontario, Canada

\section{References}

1. Hui SK, Fan CS, Christie S, Feindel CM, David TE, Ouzounian M. The aortic root does not dilate over time after replacement of the aortic valve and ascending aorta in patients with bicuspid or tricuspid aortic valves. J Thorac Cardiovasc Surg. 2018;156:5-13.e1.

2. Milewski RK, Habertheuer A, Bavaria JE, Siki M, Szeto WY, Krause E, et al. Fate of remnant sinuses of Valsalva in patients with bicuspid and trileaflet valves undergoing aortic valve, ascending aorta, and aortic arch replacement. J Thorac Cardiovasc Surg. 2017;154:421-32.

https://doi.org/10.1016/j.jtcvs.2019.01.108

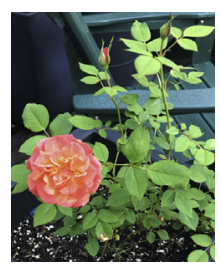

\section{WHAT'S IN A NAME? THAT WHICH WE CALL A ROSE BY ANY OTHER NAME WOULD SMELL AS SWEET}

\section{Reply to the Editor:}

I have enjoyed reading the dialog between Drs Vallabhajosyula and Ouzounian $^{1,2}$ on the management of the sinuses of Valsalva in the setting of bicuspid aortic valve in what seems to be competitive conservatism. It would appear that they are in violent agreement on the safety of leaving the left and right sinuses alone but differ perhaps on the management of the noncoronary sinus, or at least on inclusion of those with resection in their data sets. The topic appears to be what one might term "a hearty perennial." I have been interested for many years in the place of what I would call "separate valve and graft" operations in the treatment of bicuspid aortic valve and associated aortic
Author has nothing to disclose with regard to commercial support.

dilatation. ${ }^{3}$ Ouzanian calls it "AVR and RAA" (aortic valve replacement and replacement of the ascending aorta), ${ }^{1}$ whereas the group from Penn appears to be suggesting application of the term "Wheat procedure" as an alternative to "AVRSCAAR," as referenced in their 2017 publication, ${ }^{2}$ a more readily enunciated if less historically accurate moniker; the operation Wheat and colleagues ${ }^{4}$ reported excised all sinus tissue down to the annulus, apart from 2 small tongues around the coronary ostia themselves. To be fair, the confusion invited by use of my own term is obvious as well.

Irrespective of the name, for my part, I am, like Juliet, a pragmatist. If implanting a tissue prosthesis, I am inclined to extend a tongue of graft down into the noncoronary sinus, reasoning that such will simplify a subsequent reoperation if necessary by making a hockey-stick incision possible without crossing an old proximal suture line. Still I cannot argue with those who prefer to leave the noncoronary sinus intact if not significantly dilated. What does matter, I think, is leaving the sinuses surrounding the coronaries alone. It is in my experience the reimplantation of the coronaries that can create problems for the surgeon and the patient alike. Bleeding, twisting, kinking, and tension can all lead to trouble, especially if the ostia are not particularly displaced in the first place.

So, to do or not to do? With reference to the noncoronary sinus, I really do not mind. It is the coronary buttons that are the question!

Thoralf M. Sundt, $M D$

Division of Cardiac Surgery Massachusetts General Hospital Harvard Medical School Boston, Mass

\section{References}

1. Hui SK, Fan CS, Christie S, Feindel CM, David TE, Ouzounian M. The aortic root does not dilate over time after replacement of the aortic valve and ascending aorta in patients with bicuspid or tricuspid aortic valves. J Thorac Cardiovasc Surg. 2018;156:5-13.e1.

2. Milewski RK, Habertheuer A, Bavaria JE, Siki M, Szeto WY, Krause E, et al. Fate of remnant sinuses of Valsalva in patients with bicuspid and trileaflet valves undergoing aortic valve, ascending aorta, and aortic arch replacement. J Thorac Cardiovasc Surg. 2017;154:421-32.

3. Sundt TM III, Mora BN, Moon MR, Bailey MS, Pasque MK, Gay WA Jr. Options for repair of a bicuspid aortic valve and ascending aortic aneurysm. Ann Thorac Surg. 2000;69:1333-7.

4. Wheat MW Jr, Wilson JR, Bartley TD. Successful replacement of the entire ascending aorta and aortic valve. JAMA. 1964;188:717-9.

https://doi.org/10.1016/j.jtcvs.2019.01.064 